\title{
A Study to Analyze Readiness of Job-Seekers towards E- Recruitment
}

\author{
Dr. Poonam arora \\ Associate Professor, St. Kabir institute of \\ Professional Studies \\ poonam.a@skips.in \\ Chavi jain \\ Student, St. Kabir institute of Professional studies \\ Chavi19@skips.in
}

\begin{abstract}
Technology advancement in this contemporary time has made a significant impact on business operations. Every organization in this era is using internet which has not only given them an administration ease but has also enable them to efficiently focus and perform day to day business tasks. Recruitment as an integral part of any organization has also stepped into the online mode and recruiters are also now using different-tools and platforms for conducting recruitment effectively. Ranging from sharing of job description of vacancy to the e-interviews, every step in the process has become tech dependent. Hiring through internet has become a new normal and with this enhancement in technology, e-recruitment is going to be new trend. Recruiters these days are using various portals, social media tools and e-methods to recruit a candidate. But are job-seekers really finding this change easy to use?

This study specifically talks about the readiness of job seekers regarding e-recruitment and dives in further to know various platforms used by recruiters. The study majorly focuses on the perception of job seekers regarding the usage of social media, conduct of online interviews and the usage of online tools for recruitment.

The paper is based on a quantitative study conducted over a sample of 196 respondents following a descriptive research design using a structured questionnaire. The data is analyzed using ANOVA to check the significance of factors. This study tries to find the degree of acceptability of e-recruitment methods among people applying for sales jobs. The purpose of this study is to know readiness of job seekers towards e-recruitment.

The study brings out the result that majority of the job seekers don't trust the whole system of e-recruitment. According to the respondents, e-recruitment doesn't fulfills their expectations and cannot be fully trusted. The study finds that though people are ready to adopt e-recruitment as it is convenient and time/cost saving but lacks expectation fulfillment and trust side.
\end{abstract}

\section{Keywords:}

Job Seekers, Job Portals, Online Platforms, e-recruitment methods, e-recruitment tools 


\section{Introduction}

With the enhancement of technology, today online mode has made a place in every sector. Even HR department has impacted a lot which resulted into E-HRM, i.e. simply using technologies to implement the HR related policies, strategies and practices in organizations. One of the important function of HR is recruitment which basically refers to inviting the applicants, hiring them and onboarding them for a particular job or requirement in the organizations. Recruitment creates the pool of applicants and helps the organizations to find the right candidates, at right time, at right place. The recruitment as an integral part of any organization has also stepped into the online mode and so the recruiters are now using various tools, platforms or sites to advertise their vacancy.

These days, companies rely on E-Recruitment, E-Recruitment means using internet to attract and recruit the job-seekers to a particular post. E-Recruitment has enabled the organizations to focus on their major task, rather than spending more time on finding the right candidates. Recruiters are using E-Recruitment as the tool for recruitment, but do the job-seekers really find this change as acceptable? So to analyze more on this part we have done this study on readiness of job-seekers towards e-recruitment. The reason of taking only recruitment is because; it is an important function of HR and a first step in process of converting a candidate into an employee of company. Seeing this technology era, according to one research done, it says that internet has not only influenced recruiters to have a pool of candidates for their hiring, even applicants are more engaged and are very particular about company. The company's these days have their own websites and portals which attract the candidates more

Social media has made a lot of progress in this sector. Apart from e-portals such as Naukri.com, Monster.com, etc who are solely for recruitment purpose, on other hand social media has power to engage, entertain and attract more applicants. Technology has the power to ruin and make anything. If used correctly keeping everything in mind there can be much progress and so not only a HR needs to be proficient enough in using these software and social media tools but also it is important to know from job seekers side that what are their perceptions regarding these platforms and what platforms they found convenient to use and how much. Until and unless this can be known, there will be no use of using such platforms if there is not much acceptance from applicants' side.

\section{Literature review}

Human Resource is an integral and centered part of any organization. Not only in creating a talent pool but also managing, engaging, retaining and firing them the HR plays a significant role. Employees are assets of companies who later give ROI. With the introduction of technology the work of HR now becomes smooth. The traditional HR demands more of employees under an HR head to manage the other employees but nowadays e-HRM has made the work systematic and easier. Thus, e-HRM can be defined as: An umbrella concept that encompasses all potential integration processes and content between HRM and IT and it creates more value for targeted 
workers and management inside and across organizations (Agarwal, 2017). E-HRM has shifted itself towards the implementation of system called HRIS inclusion of learning management, innovation and acceptance of technology (Keebler \& Rhodes, 2002).

Corporates are relying on internet for its recruitments in the $21^{\text {st }}$ century. Electronic recruitment, commonly known as e-recruitment which is the process of selecting and recruiting potential through different modes of internet and intranet (Sangeetha, 2010). This e-recruitment can be done through different sources like company's website, social sites and job portals (Hada \& Gairola, 2015). E-recruitment has made the time and cost to be reduced creates a wider reach, increases employer's branding but on the other sides are impersonal in nature. Online mechanisms have made it easy for recruiters to search required experience, skills and abilities in their applicants while even applicants have got ease of posting their resumes online any hour of the day (Veger, 2006). One important aspect is precautions to be taken while the resume is screened online. There should be avoidance of discrimination among age, gender, religion, etc (Tyagi, 2012).

A study conducted by three researchers in 2019 resulted in majority of respondents agreeing to e-recruitment being a method increasing ease of use while there were still good number of respondents considering it to be very difficult (Akila, Vasantha \& Thirumagal, 2019). For many companies, the e-recruitment has made their task simpler, while most companies resist changes and want to continue with traditional methods only (Aguado, Rico, Rubio, VJ \& Fernandez, 2016). The procedure and the system of e-recruitment are less preferred by some of the group of applicants (Sylva \& Mol, 2009). But one study concluded that among all recruitment methods, interviews are best method to recruit right person (Shafique, O, 2012).

More usable ways to use social media should be found out by using research surveys to make this platform more effective and advantageous. Social media has gained more acceptability as its reach is tremendous in comparison with other methods. Also the acceptability among people as compared to other sources of print media. (Hosain, 2020; Hosain, Ullah \& Khudri, 2016). But the awareness regarding these job portals differs. While most users prefers job portals which are free in cost and are easy to use plus provides full information of vacancy. The perception differs with the education and the awareness, the job seekers tend to rely and trust more on these job portals. Most of the job seekers finds irrelevant to use such portals and thinks internal or reference recruiting is best for them. A survey in 2015 showed that Facebook is the most sought social network after LinkedIn and Twitter for maintaining social networks (Melanthiou, Pavlou \& Constantinou, 2015).

While talking about job portals, considering educational qualification, post graduates are having more information and knowledge of these job portals as compared to the graduates ones (Kumar, 2016). The perception differs with the education and the awareness, the job seekers tend to rely and trust more on these job portals. While most of the job seekers finds irrelevant to use such portals and thinks internal or reference recruiting is best for them.

When in conclude it can be said that, the traditional way of recruitment should not be replaced by the e-recruitment but they both should work hand in hand (Kapse, Patil \& Patil, 2012). Literature 
review finds that no specific research has been done on the perception of job seekers towards erecruitment particularly in sales sector.

\section{Objectives of research}

The whole study revolves around the e-recruitment and job-seekers readiness towards it and so the research focuses on following objectives:

1. To understand various available e-recruitment methods and tools.

2. To study and analyze the readiness of job-seekers regarding e recruitment methods.

3. To study and analyze the readiness of job-seekers regarding e-recruitment tools.

\section{Research methodology}

The research paper uses a quantitative approach of data collection using descriptive research method. For taking the opinions of the respondents, a well-structured questionnaire is prepared, containing 1 single choice question regarding best source of recruitment, along with 1 multiple option multiple choice, while for rest of the questions likert scale is used.

The ideal sample size of 196 is selected. The data collection is primary following convenience sampling method. It contains questions on the following categories:

1. Demographic details: to gain an idea about the sample through gender and age group and education qualification.

2. Variable categories: 5 likert scale based questions that are created under different categories of variable, where 3 are independent while 1 is dependent.

The study uses four different categories of parameters i.e. E-recruitment methods, e-recruitment tools (which covers e-portals and social media portals), education level as independent variable \& readiness of applicants as dependent variable under which questions pertaining to different variables are asked. Each question is asked on rating basis where preference is known through likert scale starting from strongly preferred to strongly not preferred.

Hypothesis testing:

The main aim of the study is to know the readiness of job-seekers towards e-recruitment by considering various factors. The various tools, methods and education level can impact their thought regarding accepting e-recruitment so this study addresses five hypothesis:

1. $\mathrm{H}_{01}$ :- there is no significant variance in readiness of applicants among use of e-recruitment methods.

2. $\mathrm{H}_{02}$ :- there is no significant variance in readiness of applicants among type of erecruitment tool (i.e. E-portals). 
3. $\mathrm{H}_{03}$ :- there is no significant variance in readiness of applicants among type of erecruitment tool (i.e. Social media portals).

4. $\mathrm{H}_{04}$ :- there is no significant variance in readiness of applicants among education level in terms of fulfillment of expectations.

5. $\mathrm{H}_{05}$ :- there is no significant variance in readiness of applicants among education level in terms of trust factors.

The data is collected from sample of 196 people, majority of responses (134) are in the age group of '20-25years' while rest belongs to other categories. The data is gathered from respondents who are job-seekers aspiring for sales sector and most of the respondents have masters as their education level.

\section{Measures}

$\mathrm{H}_{01}$ :- there is no significant variance in readiness of applicants among use of e-recruitment methods.

$\mathrm{H}_{\mathrm{a} 1}$ : - there is significant variance in readiness of applicants among use of e-recruitment methods.

Anova

\begin{tabular}{|c|c|c|c|c|c|c|}
\hline Source of variation & $\boldsymbol{S s}$ & $\boldsymbol{D f}$ & $\boldsymbol{M s}$ & $\boldsymbol{F}$ & $\boldsymbol{P}$-value & $\boldsymbol{F}$ crit \\
\hline Between groups & 11717.2 & 4 & 2929.3 & 10.0684 & 0.000124 & 2.866081 \\
\hline Within groups & 5818.8 & 20 & 290.94 & & & \\
\hline Total & 17536 & 24 & & & & \\
\hline
\end{tabular}

Anova table indicates that p-value (0.000124) is less than significant value (i.e. 0.05) hence, alternate hypothesis is accepted and null hypothesis is rejected. This shows that there is significant variance in readiness of applicants among use of e-recruitment methods. It means e-recruitment methods used by companies impacts the perception or readiness of job-seekers. Out of the available options virtual interviews are preferred by most by the respondents.

To measure the preference of job seekers regarding e-portals used by different companies for recruitment is measured using the following hypothesis:

$\mathrm{H}_{02}$ :- there is no significant variance in readiness of applicants among type of e-recruitment tool (i.e. E-portals).

$\mathrm{H}_{\mathrm{a} 2}$ : - there is significant variance in readiness of applicants among type of e-recruitment tool (i.e. Eportals). 
Anova

\begin{tabular}{|l|c|c|c|c|c|c|}
\hline \multicolumn{1}{|c|}{ Source of variation } & Ss & Df & Ms & F & P-value & F crit \\
\hline Between groups & 1520 & 4 & 380 & 0.591900312 & 0.671651733 & 2.75871 \\
\hline Within groups & 16050 & 25 & 642 & & & \\
\hline \multicolumn{1}{|c|}{ total } & 17570 & 29 & & & & \\
\hline
\end{tabular}

Here, anova result indicates that the significant value 0.67165 is more than 0.05 hence, the null hypothesis is accepted and alternative hypothesis is rejected. The result shows that there is no significant variance in readiness of applicants among type of e-recruitment tool (i.e. E-portals).

The third hypothesis of the study is:

$\mathrm{H}_{03}$ :- there is no significant variance in readiness of applicants among type of e-recruitment tool (i.e. Social media portals).

$\mathrm{H}_{\mathrm{a} 3}$ : - there is significant variance in readiness of applicants among type of e-recruitment tool (i.e. Social media portals).

Anova

\begin{tabular}{|c|c|c|c|c|c|c|}
\hline Source of variation & Ss & Df & Ms & F & P-value & F crit \\
\hline Between groups & 5284.333 & 4 & 1321.083 & 2.327544692 & 0.083969 & 2.75871 \\
\hline Within groups & 14189.67 & 25 & 567.5867 & & & \\
\hline Total & 19474 & 29 & & & & \\
\hline
\end{tabular}

Here, anova result indicates that the significant value 0.083969 is more than 0.05 hence, the null hypothesis is accepted and alternative hypothesis is rejected. The result shows that there is no significant variance readiness of applicants among type of e-recruitment tool (i.e. Social media portals).

To measure whether education creates an impact on readiness of use of e-recruitment among applicants, the following hypothesis is used:

$\mathrm{H}_{04}$ :- there is no significant variance in readiness of applicants among education level in terms of fulfillment of expectations.

$\mathrm{H}_{\mathrm{a} 4}$ : - there is significant variance in readiness of applicants among education level in terms of fulfillment of expectations. 
Anova

\begin{tabular}{|c|c|c|c|c|c|c|}
\hline Source of variation & $\boldsymbol{S s}$ & $\boldsymbol{D f}$ & $\boldsymbol{M s}$ & $\boldsymbol{F}$ & $\boldsymbol{P}$-value & $\boldsymbol{F}$ crit \\
\hline Between groups & 461.5 & 4 & 115.375 & 1.003697 & 0.43623 & 3.055568 \\
\hline Within groups & 1724.25 & 15 & 114.95 & & & \\
\hline Total & 2185.75 & 19 & & & & \\
\hline
\end{tabular}

The result above indicates that $\mathrm{p}$-value $(0.43623)$ is more than the alpha value $(0.05)$. Hence, the null hypothesis is accepted. The result shows that there is no significant variance in readiness of applicants among education level in terms of fulfillment of expectations.

Hence, it can be said that regardless of education qualification, there is no significant variance between education level and readiness of applicants in terms of e-recruitment fulfilling their expectations.

The questionnaire also asks about whether e-recruitment can be trusted or not, and so hypothesis framed is:

$\mathrm{H}_{05}$ :- there is no significant variance in readiness of applicants among education level in terms of trust factors.

$\mathrm{H}_{\mathrm{a} 5}$ : - there is significant variance in readiness of applicants among education level in terms of trust factors.

Anova

\begin{tabular}{|c|c|c|c|c|c|c|}
\hline Source of variation & Ss & Df & Ms & F & P-value & F crit \\
\hline Between groups & 532.5 & 4 & 133.125 & 1.04370835 & 0.417482 & 3.055568 \\
\hline Within groups & 1913.25 & 15 & 127.55 & & & \\
\hline Total & 2445.75 & 19 & & & & \\
\hline
\end{tabular}

The result above indicates that $p$-value $(0.417482)$ is more than the alpha value $(0.05)$. Hence, the null hypothesis is accepted. The result shows that there is no significant variance between education qualification and readiness of applicants (i.e. On trust factor).

Hence, it can be said that regardless of education qualification, there is no significant variance in readiness of applicants among education level in terms of trust factors. 


\section{Conclusion}

The research in the field of human resource threw up some interesting results which can be seen in the above analysis. Significant variance was found between use of e-recruitment methods and readiness of applicants as among the methods of e-recruitment, virtual interviews are preferred by most by the respondents because of the convenience and ease of not to travel and commute to the office location. Among e-portals, naukri.com is most preferred while among social media tools, it is linkedin which is preferred by respondents of this study and no variance was found among job seekers over both these variables. Unlike the evidences in literature, the study concludes that education level is not found to be a factor affecting the readiness of job seekers in using erecruitment. Also, the study reveals the fact those e-recruitment methods used by companies impacts the readiness of job-seekers while there is no significant variance between the type of erecruitment portal and readiness of applicants. There is an overall acceptance of e-recruitment among respondent, but it certainly lacks fulfillment and trust of job seekers.

\section{References}

1) Agrawal, a. (2017). Hrm effectiveness through e-hrm. In national conference on contemporary.

2) Aguado, d., rico, r., rubio, v. J., \& fernández, 1. (2016). Applicant reactions to social network web use in personnel selection and assessment. Revista de psicología del trabajo y de las organizaciones, 32(3), 183-190.

3) Akila, b., vasantha, s., \& thirumagal, p. G. (2019). Effectiveness of e-recruitment for man power selection process. Journal of critical reviews, 7(5), 2020.

4) Hada, b., \& gairola, s. (2015). Opportunities \& challenges of e-recruitment. Journal of management engineering and information technology, 2(2), 1-4.

5) Hosain, s. (2020). The impact of social media recruitment on job candidates' perceptions: evidence from bangladeshi fresh graduates.

6) Aguado, d., rico, r., rubio, vj, \&fernandez, 1. (2016). Applicant reaction to social network web use in personnel selection and assessment, 32(3), 183-190.

7) Hosain, s., ullah, k., \& khudri, m. (2016). The impact of e-recruitment on candidates' attitudes: a study on graduate job seekers of bangladesh. Journal of human and social science research, 8(01), 009-017.

8) Kapse, a. S., patil, v. S., \& patil, n. V. (2012). E-recruitment. International journal of engineering and advanced technology, 1(4), 82-86. 
9) Keebler, t. J., \& rhodes, d. W. (2002). E-hr: becoming the" path of least resistance". Employment relations today, 29(2), 57.

10) Kumar, s. V. S. Students awareness towards career creation with job portals.

11) Melanthiou, y., pavlou, f., \& constantinou, e. (2015). The use of social network sites as an e-recruitment tool. Journal of transnational management, 20(1), 31-49.

12) Sylva, h., \& mol, s. T. (2009). E-recruitment: a study into applicant perceptions of an online application system. International journal of selection and assessment, 17(3), 311-323.

13) Sangeetha, k. (2010). Effective recruitment: a framework. Iup journal of business strategy, 7.

14) Shafique, o. (2012). Recruitment in the 21st century. Interdisciplinary journal of contemporary research in business, 4(2), 887-901.

15) Tyagi, a. (2012). Effective talent acquisition through e-recruitment: a study. International journal of multidisciplinary research, 2(3), 302-312.

16) Veger, m. (2006). How does internet recruitment have effect on recruitment performance? In fourth twente student conference on it (vol. 30). 